\title{
CARACTERIZAÇÃO GEOECOLÓGICA COMO SUBSÍDIO PARA ESTUDOS AMBIENTAIS EM RPPNS: ESTUDOS DE CASOS NO PARANÁ ${ }^{1}$
}

\author{
Maristela Moresco Mezzomo², Kamila Walter Ghisso³ e Diego Vinícius Campos ${ }^{3}$
}

\begin{abstract}
RESUMO - A caracterização do meio físico de unidades de conservação apresenta-se como importante aspecto para o planejamento de ações de gestão ambiental, devendo, inclusive, constar no plano de manejo. Porém, muitas unidades de conservação não contam com esse plano. Nessa perspectiva, este artigo apresenta a técnica de caracterização geoecológica, por meio da construção de perfis geoecológicos, como método para o levantamento e reconhecimento do meio físico de unidade de conservação, em especial para Reservas Particulares do Patrimônio Natural (RPPNs). Este estudo foi aplicado nas RPPNs Artur Cesar Vigilato/Fazenda Santa Terezinha e Artur Cesar Vigilato/Fazenda Mangueira, localizadas, respectivamente, nos Municípios de Luiziana e Campo Mourão, Estado do Paraná. Os resultados possibilitaram reconhecer como é a organização vertical e horizontal dos elementos da paisagem das áreas, os quais foram representados visualmente nos perfis geoecológicos. Além disso, foi possível compreender a dinâmica das RPPNs, no que tange aos riscos ambientais, possibilitando a organização de informações e dados que poderão subsidiar outros estudos ambientais.
\end{abstract}

Palavras-chave: Campo Mourão; Luiziana; Plano de Manejo.

\section{GEO-ECOLOGICAL CARACTERIZATION AS SUBSIDY FOR ENVIRONMENTAL STUDIES IN RPPNS (in Portuguese): CASE STUDIES IN PARANA}

\begin{abstract}
The characterization of the physical environment of conservations units comes as an important aspect for environmental management planning, and it should even be included in the management plan. However, many conservations units do not have a management plan. In this perspective, this article presents the technique of geo-ecological characterization by building geo-ecological profiles as a survey and recognition method of the physical environment of conservation unit, especially for Private Reserves of Natural Heritage (RPPNs in Portuguese). The study was applied in the RPPNs Artur Cesar Vigilato/Fazenda Santa Terezinha and Artur Cesar Vigilato/Fazenda Mangueira, located in the municipalities of Luiziana/PR and Campo Mourão/ $P R$, respectively. Results had shown how the vertical and horizontal organization of landscape elements are, which were being visually represented in the geo-ecological profiles. Furthermore it was also possible to understand the RPPNs dynamics regarding environmental risks, enabling information and data organization that could subsidize other environmental studies.
\end{abstract}

Keywords: Campo Mourão; Luiziana; Management Plan.

\footnotetext{
${ }^{1}$ Recebido em 29.08.2012 aceito para publicação em 07.08.2014.

${ }^{2}$ Departamento Acadêmico de Ambiental, Universidade Tecnológica Federal do Paraná, Câmpus Campo Mourão, Brasil. E-mail: <mezzomo@utfpr.edu.br>.

${ }^{3}$ Graduandos em Engenharia Ambiental, Universidade Tecnológica Federal do Paraná, Câmpus Campo Mourão, Brasil. E-mail: <kamilawg@hotmail.com> e <diegoviniciuscampos@gmail.com>.
} 


\section{INTRODUÇÃO}

O Brasil é um dos países mais ricos do mundo em megadiversidade, concorrendo com a Indonésia pelo título de nação biologicamente mais rica do planeta (MITTERMEIER, 2005). No entanto, como destacou esse mesmo autor, o país tem atraído mais atenção pelas vastas áreas desmatadas, conversão de paisagens naturais em reflorestamentos, plantações de soja, aumento de área de pastagens e expansão industrial do que pelas ações de conservação. Diante desse cenário, técnicas inovadoras com ênfase na proteção ambiental vêm crescendo consideravelmente. Esse crescimento tem relação direta com a demanda pela construção de metodologias eficientes, as quais se constituem um dos principais desafios enfrentados na área ambiental (ANDRADE, 2004).

Entre esses desafios estão os estudos que buscam contribuir para a conservação dos elementos (recursos) naturais em Unidades de Conservação (UCs). No Brasil, as UCs fazem parte do Sistema Nacional de Unidades de Conservação, sendo agrupadas em duas categorias: UCs de proteção integral e UCs de uso sustentável. Dentro da categoria de uso sustentável estão as Reservas Particulares do Patrimônio Natural (RPPNs), caracterizadas por serem áreas privadas e gravadas com perpetuidade. Tanto as RPPNs quanto as demais categorias de UCs apresentam importantes funções ambientais, como: preservar os recursos hídricos, a estabilidade geológica, a biodiversidade e o solo e proteger as espécies ameaçadas de extinção (BRASIL, LEI 9.985/2000). Devido a essas diversas funções, as UCs, em especial as RPPNs, têm-se constituído como objetos de estudo de diferentes áreas científicas, como a Biologia, a Geografia e as Engenharias Florestal e Ambiental. Esta última tem apresentado variados focos de interesse, como levantamentos de fauna e flora, análises com aplicação de sistema de informação geográfica e estudos geoecológicos. Este último foco vem-se destacando por apresentar uma técnica inovadora para a área, denominada Perfil Geoecológico.

O Perfil Geoecológico é técnica de interpretação integrada das características ambientais de determinada paisagem, sendo considerada ferramenta para análise e diagnóstico ambientais. Por meio de um perfil geoecológico, é possível representar cartograficamente secções de determinada área e fazer correlações entre os geoelementos de interesse (topografia, vegetação, pedologia, estrutura geológica etc.) representados por transectos que compõem o perfil. Como esses transectos são distribuídos de maneira sequencial, as informações (horizontais e verticais) podem ser integradas para interpretar as condições ambientais atuais de determinado local, como também do ecossistema (LEVIGHIN; VIADANA, 2002/2003).

Conforme expuseram Silveira e Silva (2010, p. 1026), "o entendimento da interação entre os fatores físicos, antrópicos e da cobertura vegetal em uma paisagem é de fundamental importância para oferecer subsídios ao planejamento territorial de forma sustentável”. O conhecimento da estrutura geoecológica da paisagem, por meio da construção de um ou mais perfis, fornece importantes informações que irão subsidiar análises ambientais e, assim, colaborar com projetos de planejamento em relação às atividades socioeconômicas. A aplicação dessa técnica pode ter diversos recortes espaciais e diferentes escalas (MANOSSO; NÓBREGA, 2008; MANOSSO, 2008), ou seja, é possível construir perfis geoecológicos, tendo como recorte um território municipal ou uma RPPN, como foi o foco deste trabalho.

De acordo com o SNUC (BRASIL, LEI 9.985/2000), entre os objetivos das RPPNs está a conservação da diversidade biológica, sendo permitido, dentro de seus limites, o desenvolvimento de pesquisa científica e visitação com fins turísticos, recreativos e educacionais, desde que previstas no plano de manejo. Este, por sua vez, é um documento técnico que estabelece o zoneamento e as normas relativas ao uso da área, dos recursos naturais nela existentes, da zona de amortecimento e dos corredores ecológicos.

No Estado do Paraná, as RPPNs foram classificadas como UCs de proteção integral (PARANÁ, DECRETOS $\mathrm{N}^{\circ}$. 4.890/05 e $\mathrm{N}^{\circ}$. 1529/07), conforme permite o $\S 5^{\circ}$ do Art. 22 da Lei 9.985/00. Essa mudança de categoria promoveu alteração nos objetivos dessas áreas que passaram a apresentar as seguintes atividades: pesquisa científica com fins conservacionistas, turismo sustentável, educação, treinamento e capacitação, recreação (em especial para portadores de necessidades especiais), restauração e recuperação ambiental.

Essa mudança de categoria, teoricamente, amplia o nível de proteção das RPPNs, uma vez que as UCs de proteção integral apresentam mais limitações de uso. Porém, ao comparar as atividades contidas no SNUC e no Decreto Estadual, percebe-se que a mudança de categoria não restringiu as atividades na prática, 
possibilitando, inclusive, ampliar as possibilidades de uso. No Decreto Estadual, as atividades ampliam o acesso de pessoas, já que envolve, além do turismo, educação e recreação, o treinamento e capacitação de pessoas. Outra diferença em relação ao SNUC se refere ao objetivo voltado para a restauração e recuperação ambiental. Esse conjunto de atividades apresenta um conflito de objetivos, pois, ao mesmo tempo que possibilita ações com maior envolvimento com a sociedade, prevê a restauração e recuperação, as quais são ações que requerem usos restritos.

Diante desse contexto em que estão inseridas as RPPNs do Paraná, parte-se do entendimento de que todas as ações ou atividades desenvolvidas dentro dessas UCs devem ser planejadas, tendo em vista, principalmente, os aspectos ambientais, uma vez que são áreas protegidas. Para tanto, a fim de obter sucesso na conservação da biodiversidade de uma reserva, é importante que haja o planejamento ambiental. No caso das RPPNs, o planejamento deve ser contínuo, gradativo e flexível, pois seu desenvolvimento depende do interesse do proprietário e dos objetivos da área, os quais devem constar no plano de manejo, que é o principal documento de uma UC (FERREIRA et al., 2004).

Embora, no entanto, seja uma exigência legal, a elaboração do plano de manejo ainda apresenta muitas dificuldades, pois requer estudos multidisciplinares e demanda tempo e recursos financeiros (MEDEIROS; PEREIRA, 2011), uma fez que precisa envolver a caracterização dos aspectos físicos, biológicos e antrópicos da área. Sem o conhecimento dessas características, não há como prever ações e atividades na UC. Para tanto, em relação aos aspectos físicos, o conhecimento das características geoecológicas constitui uma forma direta para compor o conjunto de informações, que posteriormente irão subsidiar o planejamento das ações e, ou, atividades desenvolvidas.

Nesse sentido, considerando a importância que os planos de manejo têm para o planejamento de ações, tendo em vista o cumprimento das funções de uma UC e o fato de os estudos geoecológicos contribuírem para a caracterização do meio físico, a técnica de perfil geoecológico foi aplicada em duas RPPNs localizadas nos Municípios de Campo Mourão e Luiziana, no Estado do Paraná. O objetivo foi fazer a caracterização geoecológica por meio de perfis, com o intuito de verificar a eficiência da técnica, bem como possibilitar a organização de informações e dados do meio físico dessas áreas para subsidiar outros trabalhos, como no caso da elaboração do plano de seu manejo. Os resultados foram satisfatórios, pois foi possível avaliar que a técnica de perfil geoecológico constitui ferramenta eficiente para estudos de levantamento e caracterização da área ambiental. Além disso, o levantamento de informações e dados e a caracterização geoecológica realizados possibilitaram reconhecer como é a distribuição vertical e horizontal dos elementos da paisagem das RPPNs.

\section{MATERIALE MÉTODO}

Este trabalho contou com a abordagem sistêmica como método de estudo, buscando analisar, de forma integrada, as informações contidas na literatura, as características levantadas sobre as áreas e as observações de campo (BERTRAND, 1971; MATEO RODRIGUES et al., 2004).

A primeira etapa da pesquisa envolveu a organização da base teórico-metodológica, por meio de pesquisa em livros, artigos científicos, teses, dissertações e documentos. Os principais temas abordados nesta fase foram: Paisagem(BERTRAND, 1972; MEZZOMO, 2010), Unidades de Conservação (LEI N 9.985/00), RPPNs (LEI No.9.985/00; DECRETO, Nº. 5.746/06), Perfil Geoecológico (LEVIGHIN; VIADANA, 2002/2003; MANOSSO, 2008; MEZZOMO, 2009) e Plano de Manejo (FERREIRA et al., 2004; IAP, 2009; MEDEIROS; PEREIRA, 2011).

Posteriormente, definiram-se os locais de aplicação do estudo (RPPNs) e, por meio do software Google Earth, realizou-se a delimitação das áreas. Após essa etapa, foram feitos levantamentos sobre as características geoecológicas de cada RPPN em sites de órgãos públicos oficiais (MINEROPAR, IAPAR, ITCG, IAP) ${ }^{1}$. Entre os materiais utilizados para o levantamento estão: Cartas Topográficas de Campo Mourão e Luiziana, com escala de 1:50.000 (1990); Mapa Geológico do Paraná, com escala de 1:3.000.000 (2001); Carta Geomorfológica Folha Campo Mourão, com escala de 1:500.000 (2006); Mapa Geomorfológico do Estado do Paraná, com escala de 1:650.000 (2006); e Mapa de Vulnerabilidade Geoambiental do Estado do Paraná, com escala de 1:650.000 (2007). Também, foram feitos trabalhos de campo nas RPPNs, onde se coletaram informações, por meio de visualização in loco, sobre o uso do solo, distribuição da cobertura vegetal, presença de afloramentos rochosos e solo exposto, características 
da drenagem e formas das vertentes, além de problemas ou riscos ambientais, a fim de fazer uma comparação com as informações coletadas na literatura.

Após essas etapas, foram elaborados os perfis geoecológicos, seguindo as seguintes fases: 1) organização das informações obtidas; 2) definição do marco inicial e final de cada perfil topográfico, utilizando o software Google Earth; 3) confecção e organização dos perfis topográficos, utilizando os softwares Global Mapper 12, Adobe Photoshop CS5.1 e Corel Draw 12; e 3) confecção dos perfis geoecológicos, utilizando o software Corel Draw 12.

Com a base teórico-metodológica organizada e os perfis geoecológicos prontos, foi feita a análise integrada das informações e organização do texto, considerando-se o enfoque geoecológico também encontrado em Levighin e Viadana (2002/2003), Manosso (2008), Mezzomo (2009) e Silveira e Silva (2010).

\section{RESULTADOS}

\section{1. Áreas de Estudo}

O estudo foi desenvolvido em duas RPPNs estaduais de propriedade da família de Artur Cesar Vigilato. As RPPNs homônimas ao dono estão localizadas nas Fazendas Mangueira, no Município de Campo Mourão; e Santa Terezinha, no Município de Luiziana. Os dois municípios fazem parte da mesorregião centro-ocidental do Paraná, e parte de seus territórios compõe a Bacia Hidrográfica do Rio Mourão. Esse rio serve de limite entre os Municípios de Campo Mourão e Luiziana, sendo o principal rio da região devido à presença da Usina Hidrelétrica Mourão I, que forma um reservatório com 1.273,65 ha (Figura 1).

A partir de 1997, as áreas correspondentes à usina e ao reservatório passaram a constituir o Parque Estadual Lago Azul. Como um dos objetivos do parque é promover o estabelecimento de novas áreas protegidas no seu entorno, com a formação de corredores ecológicos, o órgão ambiental estadual (IAP) incentivou a criação de sete RPPNs em 1998, entre as quais estão as duas em estudo (Portarias IAP n ${ }^{\circ}$. 165/1998 e nº. 189/1998).

Ambas as RPPNs estão nas zonas rurais de seus municípios. A RPPN localizada em Luiziana (Fazenda Santa Terezinha) possui 72,6 ha e margeia o rio Mourão, estando a jusante da Fazenda Mangueira. A RPPN localizada no Município de Campo Mourão (Fazenda
Mangueira) possui 108,90 ha de área (divididos em dois fragmentos) e situa-se nos rios Mato Queimado e Ribeirão Canguçu, que são importantes afluentes do rio Mourão.

\subsection{Caracterização Geoecológica}

A caracterização geoecológica consiste em apresentar informações sobre substrato rochoso, formas de relevo, tipo de solo, hidrografia, classificação e características climáticas, composição fitogeográfica, tipo de uso do solo e problemas ou riscos ambientais.

O conhecimento das características geoecológicas das áreas, feito por levantamento de informações e trabalho de campo, somado à construção de perfis topográficos (Figura 2), possibilitou a construção dos perfis geoecológicos.

Fonte: GOOGLE EARTH, 2007. Organizado pelos autores, 2012. Source: GOOGLE EARTH, 2007. Organized by the authors, 2012.

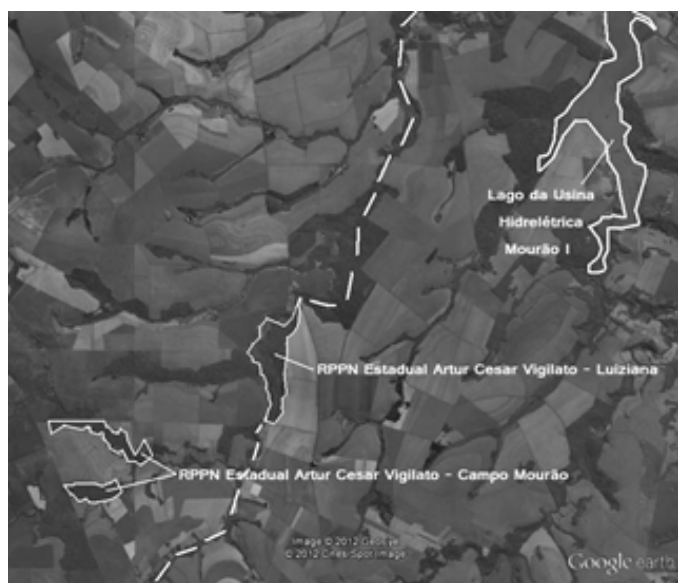

Figura 1 - Localização dos dois fragmentos que compõem aRPPNEstadual ArturCesarVigilato-FazendaMangueira (Campo Mourão) e a RPPN Estadual Artur Cesar Vigilato - Fazenda Santa Terezinha (Luiziana), em relação ao lago da Usina Hidrelétrica Mourão I. O tracejado indica o rio Mourão, que também serve como limite territorial entre os Municípios de Campo Mourão (à esquerda) e Luiziana (à direita).

Figure 1 - Localization of two fragments from the State RPPN (in Portuguese) Artur Cesar Vigilato - Fazenda Mangueira (Campo Mourão), and the State RPPN (in Portuguese) Artur Cesar Vigilato - Fazenda Santa Terezinha (Luiziana), relative to the lake of the Hydroelectric Plant Mourão. The dashed line indicates the river Mourão, which is also a territorial limit between the municipalities of Campo Mourão (on the left) and Luiziana (on the right). 
Fonte: GOOGLE EARTH, 2007. Organizado pelos autores, 2012. Source: GOOGLE EARTH, 2007. Organized by the authors, 2012.

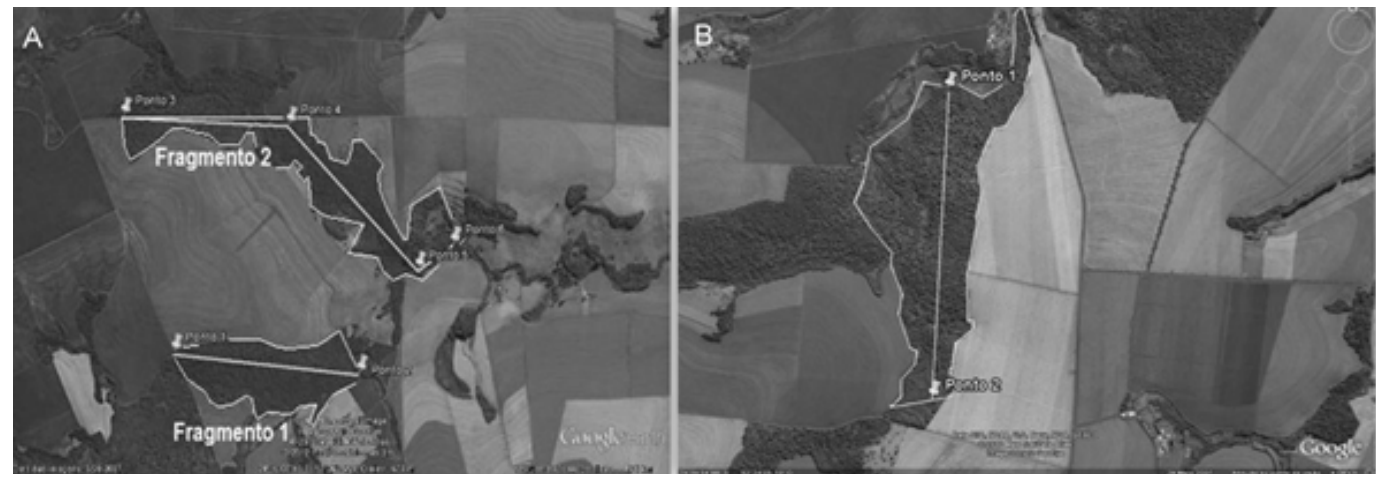

Figura 2 - Transectos dos perfis topográficos, RPPN Estadual Artur Cesar Vigilato - Fazenda Mangueira (Campo Mourão) (A) e RPPN Estadual Artur Cesar Vigilato Fazenda Santa Terezinha (Luiziana) (B).

Figure 2 - Transects of the tophografic profiles, State RPPN (in Portuguese) Artur Cesar Vigilato - Fazenda Mangueira (Campo Mourão) (A) and State RPPN (in Portuguese) Artur Cesar Vigilato - Fazenda Santa Terezinha (Luiziana) (B).

As informações contidas nos perfis geoecológicos (Figuras 3, 4 e 5) constituem um resumo do que foi pesquisado. A forma de exposição das informações nos perfis tem o intuído de demonstrar, visualmente, como é a distribuição vertical e horizontal dos elementos da paisagem das RPPNs. As informações permitem elaborar interpretações e análises sobre as características geoecológicas de forma dinâmica.

Como as duas RPPNs estão localizadas próximas, não há muita variação das características dos elementos que compõem a paisagem. Entre as pequenas diferenças, pode-se destacar a base geológica, pois, enquanto a RPPN Fazenda Santa Terezinha está somente sobre a Formação Serra Geral do Grupo São Bento, a RPPN Fazenda Mangueira se localiza em uma zona de transição dessa base geológica com a Formação Caiuá do Grupo Bauru. A Formação Caiuá tem rocha do tipo arenito, que varia de fino a médio. Já a Formação Serra Geral conta com rochas efusivas basálticas toleíticas com basaltos de estrutura maciça e amigdaloide, de textura afanítica, sendo essas rochas oriundas de derrames de vulcanismo de fissura continental. Consequentemente, oriundas dessas formações diferentes, as classes de solo também vão variar; no caso da RPPN Fazenda Santa Terezinha, há o predomínio do Latossolo Vermelho Distroférrico, enquanto na RPPN Fazenda Mangueira predomina o Argissolo Vermelho Distrófico.

Outra característica diferenciada e que merece destaque se refere à fitogeografia. Na RPPN Fazenda Mangueira, a vegetação é classificada como Floresta

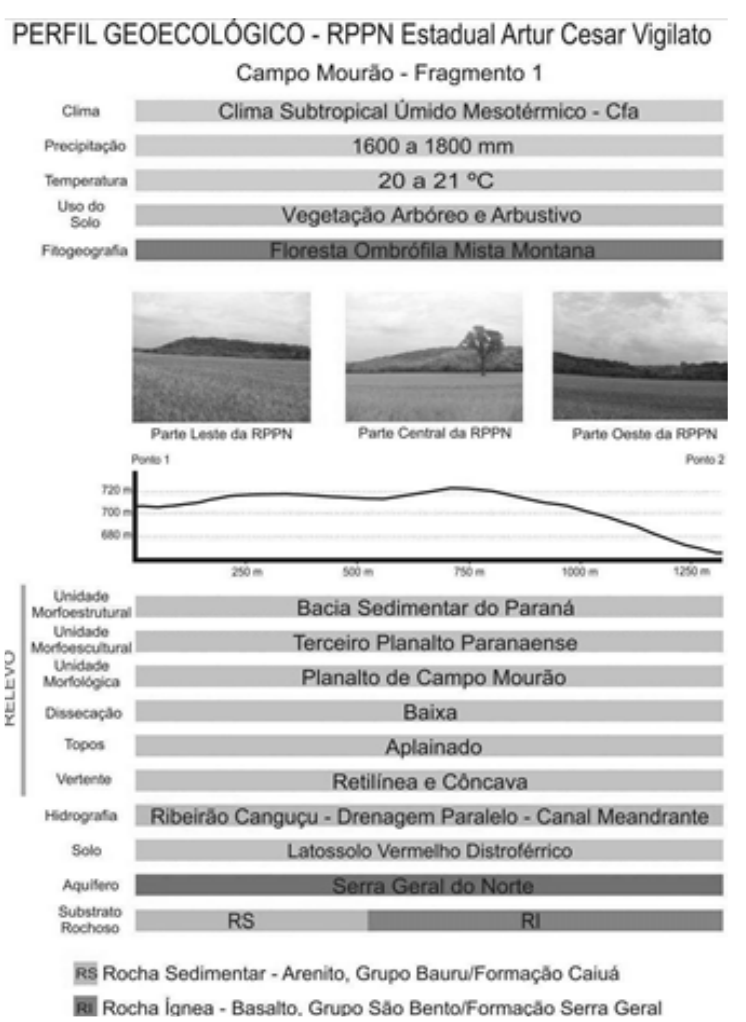

Figura 3 - Perfil Geoecológico do Fragmento 1, RPPN Estadual Artur Cesar Vigilato - Fazenda Mangueira (Campo Mourão)

Figure 3-Geo-ecological Profile of the Fragment 1, RPPN (in Portuguese) Artur Cesar Vigilato-Hose Farm (Campo Mourão).

Revista Árvore, Viçosa-MG, v.38, n.5, p.907-917, 2014 


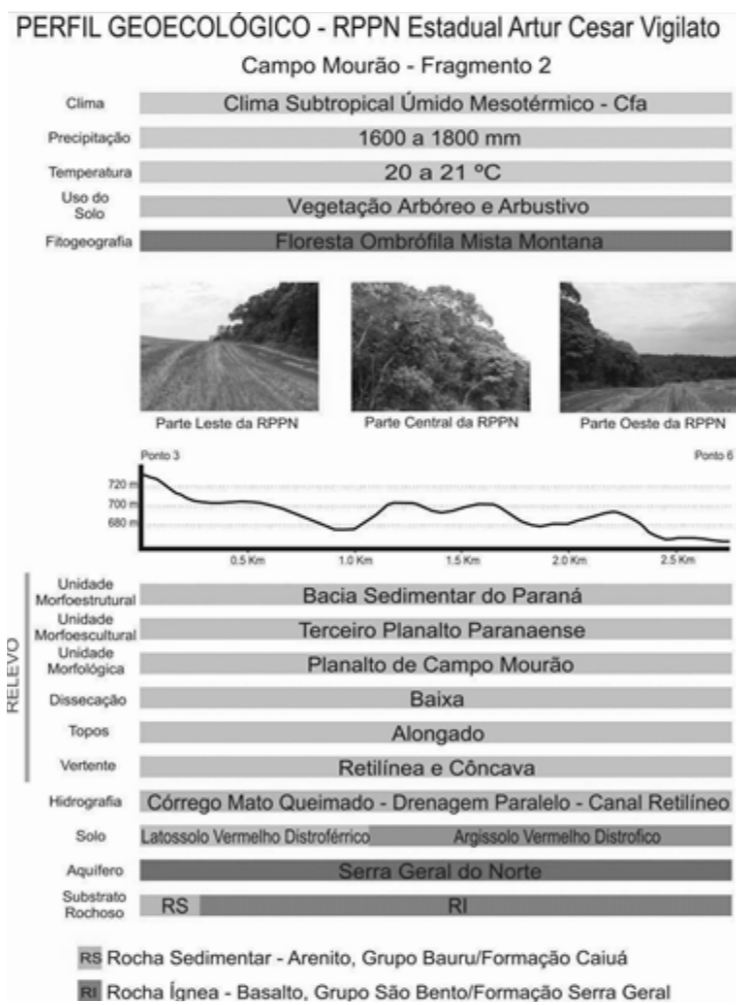

Figura 4-Perfil Geoecológico do Fragmento 2, RPPN Estadual Artur Cesar Vigilato - Fazenda Mangueira (Campo Mourão).

Figure 4-Geo-ecological Profile of the Fragment 2, State RPPN (in Portuguese) Artur Cesar Vigilato - Fazenda Mangueira (Campo Mourão).

Ombrófila Mista Montana, enquanto na RPPN Fazenda Santa Terezinha ela se apresenta com fisionomia de zona de transição entre Floresta Ombrófila Mista e Floresta Estacional Semidecidual (ITCG, 2009; SILVA, 2009). Em ambas foi observada a presença da Araucaria angustifolia (Bertol.) Kuntze, espécie característica da Floresta Ombrófila Mista. Em estudo realizado na RPPN Fazenda Santa Terezinha, em 2009, foram identificadas 139 espécies de plantas vasculares, com a predominância das famílias Asteraceae, Solanaceae e Lamiaceae (SILVA, 2009).

\section{DISCUSSÃO}

A organização dos elementos do meio físico no formato do perfil permitiu que se obtivesse melhor compreensão sobre a organização da paisagem das RPPNs, bem como verificar a dinâmica em que os elementos estão envolvidos. Os trabalhos de campo
PERFIL GEOECOLOGICO - RPPN Estadual Artur Cesar Vigilato Luiziana
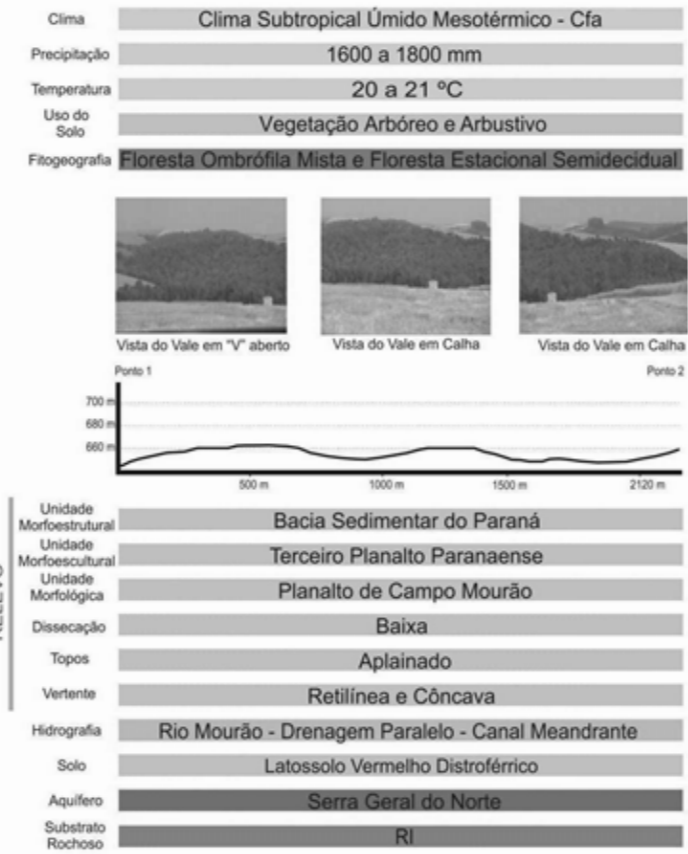

RII Rocha ígnea - Basalto, Grupo São Bento/Formaçăo Serra Geral

Figura 5 - Perfil Geoecológico da RPPN Estadual Artur Cesar Vigilato - Fazenda Santa Terezinha (Luiziana).

Figure 5 - Geo-ecological Profile of the State RPPN (in Portuguese) Artur Cesar Vigilato - Fazenda Santa Terezinha (Luiziana).

realizados nas áreas proporcionaram conferir e analisar as informações contidas na literatura e nos materiais utilizados, possibilitando facilitar a análise integrada e a descrição da paisagem das áreas.

A caracterização geoecológica, por meio do uso do perfil geoecológico, demonstrou como é a distribuição vertical e horizontal da paisagem, evidenciando a organização da sua estrutura. O conhecimento sobre as características por meio da análise das relações entre os elementos físicos (rocha, solo, relevo, sistema hídrico e clima), a vegetação e as atividades inerentes ao homem, principalmente de uso e ocupação do solo, auxiliaram a identificação de riscos e problemas ambientais das áreas.

Conforme observado em campo, o tipo de uso do solo dentro das RPPNs é somente feito por vegetação, não havendo nenhuma atividade antrópica. No entorno das áreas existem, predominantemente, lavouras temporárias (milho, soja e trigo), que apresentam algumas 
restrições e fiscalização. Essas restrições estão relacionadas com o fato de as RPPNs estarem localizadas na Zona de Amortecimento (ZA) do Parque Estadual Lago Azul.

Segundo o SNUC, Zona de Amortecimento é “o entorno de uma unidade de conservação, onde as atividades humanas estão sujeitas a normas e restrições específicas, com o propósito de minimizar os impactos negativos sobre a unidade” (BRASIL, Lei 9.985/2000, p. 2). De 1998 até o ano 2010, as RPPNs em estudo faziam parte da ZA do Parque Estadual Lago Azul. A partir de 2010, a ZA teve sua área reduzida, passando de 83 mil ha para 8 mil ha. Como ainda não foi desenvolvido o novo mapeamento, não se pode confirmar se as duas RPPNs continuam ou não nesse perímetro. Porém, em um rápido cálculo, acredita-se que ambas podem ter ficado fora da nova ZA. Mas, anteriormente a essa mudança, elas faziam parte da ZA e, por isso, por cerca de 10 anos, estavam dentro de um contexto de exigências em relação ao uso do entorno.

Em uma ZA, a utilização de agrotóxico deve ser reduzida, e não se pode exercer a plantação de alimentos geneticamente modificados nem a criação de espécies exóticas de peixes, anfíbios e répteis. De acordo com IAP/DIBAP (2005, p. 30-32/IV), “as propriedades com cultivos de espécies exóticas potencialmente invasoras deverão providenciar o controle da expansão destas espécies para se evitar a dispersão para outras áreas e/ou locais a fim de minimizar o impacto sobre o meio ambiente”.

A presença de espécies vegetais exóticas invasoras em uma UC tende a tornar-se um grande problema, pois elas basicamente ocupam o lugar das plantas nativas, lutando por água e nutrientes e afetando a relação do polinizador com a planta. Isso faz que o principal propósito de uma UC, que é a conservação da biodiversidade, perca sua eficácia. Além disso, a presença dessas espécies pode provocar danos físicos à área, como erosão do solo, sedimentação, mudança no regime de incêndio, no ciclo hidrológico e no balanço energético, além de provocar perda do valor econômico e estético da propriedade, comprometendo seu potencial turístico. Diante desses danos, o manejo da propriedade precisa ser revisto, passando a incluir um sistema permanente de controle e prevenção da chegada de espécies exóticas invasoras, assim como um diagnóstico das que já estão presentes no local (ZILLER, 2006).
O estudo florístico realizado na RPPN localizada em Luiziana, usado como base para a elaboração do perfil geoecológico, apontou para a presença de 14 espécies exóticas invasoras no local: Solidago sp., Euphorbia heterophylla L., Ricinus communis L., Croscomia croscosmiflora (Nichols) N. E. Brown, Leonotis nepetifolia (L.) W.T. Aiton, Leonurus sibirucus L., Lilium regale E. H./Wilson, Melia azedarach L., Mirabilis jalapa L., Talinum paniculatum (Jacq) Gaertn., Hovenia dulcis Thunberg, Cardiospermum halicacabum L., Thelypteris dentata (forsk) St. John. e Hedychium coronarium J. Konig (SILVA, 2009). Quanto à RPPN localizada em Campo Mourão, ainda não foram desenvolvidos estudos sobre a flora, no entanto visitas in loco permitiram constatar a presença da espécie exótica invasora denominada Ricinus communis L. (popularmente conhecida como mamona).

Essas informações sobre as espécies exóticas invasoras, aliadas às informações sobre o tipo de solo e uso, características geológicas e geomorfológicas, bem como as observações em campo, possibilitaram fazer algumas considerações sobre os riscos ambientais a que as RPPNs estão expostas:

- Processos erosivos lineares no entorno das áreas, devido à existência de estradas rurais não pavimentadas em direção paralela às vertentes, promovendo, assim, processos morfogenéticos.

- Processos erosivos laminares e lineares, devido à existência de áreas com solo exposto em alguns períodos do ano (entre safra) e manejo, sem uso efetivo de terraceamentos.

- Assoreamentos de rios provocados pelo carregamento de sedimentos vindo das áreas adjacentes.

- Contaminação dos corpos hídricos e ameaça à fauna e flora, devido ao uso de produtos químicos.

- Presença de espécies invasoras e exóticas invasoras que ameaçam as espécies nativas.

Esses riscos estão relacionados tanto às características geoecológicas da paisagem em que as RPPNs estão inseridas quanto ao tipo de uso e manejo que são feitos.

Em relação ao uso e manejo, observou-se que o uso intensivo pela agricultura, sem a presença de manejo adequado (terraceamentos e plantio direto), promove situações em que o solo fica exposto à ação das águas

Revista Árvore, Viçosa-MG, v.38, n.5, p.907-917, 2014 
pluviais e, assim, sofra com o escoamento superficial laminar ou concentrado, que é acelerado pela falta de contenção da energia potencial da água, que deveria ser feita pelos terraceamentos. Assim, potencializa-se o escoamento superficial e, consequentemente, o carregamento de sedimentos para dentro das RPPNs e dos corpos hídricos.

Verificou-se que a RPPN localizada na Fazenda Mangueira (fragmentos 1 e 2), por apresentar transição entre solos, pode estar mais vulnerável a problemas relacionados à erosão, devido à presença da classe de solo Argissolo Vermelho distrófico. Além disso, os dois fragmentos estão localizados no setor de média alta a baixa vertente, fazendo que as declividades sejam maiores do que se fossem localizadas em área de topo. Essa condição topográfica pode facilitar a instalação de processos de erosão linear ou, mesmo, movimentos de massa.

No caso da RPPN da Fazenda Terezinha, como está localizada em baixa vertente, não apresenta risco de movimentos de massa, tendo ainda menor risco em relação aos processos erosivos lineares e laminares. Entretanto, como parte de sua área está na planície aluvial do rio Mourão, apresenta maior vulnerabilidade a processos de assoreamento do rio. Dentro de seus limites, foram verificados meandros abandonados, o que indica que o sistema hídrico é dinâmico e, por isso, merece cuidados conservacionistas para evitar problemas com assoreamento tanto dentro da área da RPPN quanto, principalmente, a montante do rio.

Outro risco evidenciado nas observações de campo se refere ao uso de agrotóxico, que é feito no entorno das duas RPPNs. Esse produto pode ser levado até a mata, por meio da ação do vento e das águas pluviais por escoamento superficial e subsuperficial, podendo contaminar os rios e, consequentemente, causar a morte da fauna aquática e de espécies vegetais. Como a agricultura do entorno apresenta características de ser intensiva, mecanizada e com emprego de alta tecnologia (agricultura de precisão), estima-se que o uso de produtos químicos, como fertilizantes, pesticidas, praguicidas, desfolhantes e dessecantes, seja constante e, por isso, a existência desse tipo de risco.

Esses riscos ambientais verificados em relação às RPPNs terão maior ou menor desenvolvimento, dependendo da forma como a gestão das áreas é procedida, bem como em relação ao uso do entorno. De acordo com Medeiros e Pereira (2011, p. 286), “a gestão de áreas protegidas é um processo contínuo e necessário (...). Contudo, ele demanda planejamento, organização e recursos humanos e financeiros”. No caso da gestão e planejamento ambiental, ambos devem ser realizados para que se possa elaborar o plano de manejo, cuja implementação é obrigatória em toda a RPPN, no prazo de cinco anos após a sua criação.

De acordo com o SNUC (BRASIL, LEI, N. 9.985/ 2000, p. 2), “o Plano de Manejo deve abranger a área da unidade de conservação, sua zona de amortecimento e os corredores ecológicos, incluindo medidas com o fim de promover sua integração à vida econômica e social das comunidades vizinhas". O profissional, ou profissionais, que for elaborar um plano de manejo precisa ter amplo conhecimento sobre o assunto, sobre a área e sobre a prática de planejamento. Assim, dentro das possibilidades de elaboração do plano de manejo, todas as informações deverão ser georreferenciadas (FERREIRA et al., 2004).

Reconhecendo essa importância em relação ao plano de manejo, o Instituto Ambiental do Paraná (IAP) elaborou um roteiro para planejamento das RPPNs do Estado, com destaque para a elaboração de planos de manejo, em que se sugerem três modelos nomeados como A, B e C: O modelo A tem como objetivo a proteção dos recursos naturais; o B visa pesquisas cientificas conservacionistas (educação, treinamento e capacitação); e o C soma aos objetivos do B a implementação do turismo sustentável e a recreação, contemplando pessoas portadoras de necessidades especiais (IAP, 2009). Essa orientação atende ao que propõe o SNUC, quando indica que os órgãos ambientais estaduais devem apoiar na elaboração do plano de manejo de RPPNs.

Esse reconhecimento por parte do órgão ambiental demonstra que as RPPNs do Paraná contam com apoio político-institucional importante, tanto para a criação quanto para a manutenção das áreas. O que se percebe, porém, é que na prática as ações voltadas para a elaboração de planos de manejo ainda está aquém do ideal, uma vez que das 222 RPPNs presentes no Estado, menos de 10\% tem planos de manejo (IAP, 2012).

Como as duas RPPNs não apresentam planos de manejo, entende-se que há a necessidade urgente de esses documentos serem elaborados, tendo em vista 
a manutenção das funções dessas áreas (preservação dos recursos hídricos, estabilidade geológica, biodiversidade, solo) e os riscos ambientais verificados.

É conhecido que, para ser elaborado de forma plena, o plano de manejo necessita do trabalho de uma equipe multidisciplinar que, além dos aspectos ambientais, aborde temas sociais e econômicos. Nessa perspectiva, a contribuição desta pesquisa está relacionada com o levantamento e caracterização geoecológica das áreas, que podem ser desenvolvidas com o uso da técnica apresentada.

\section{CONCLUSÃO}

A caracterização geoecológica realizada, usando como técnica a construção de perfis geoecológicos, possibilitou compreender como é a distribuição dos elementos de determinada paisagem, tanto de maneira vertical quanto horizontal. Isso levou a uma melhor compreensão sobre a estrutura da paisagem, que no caso em estudo teve como recorte espacial as RPPNs Artur Cesar Vigilato - Fazenda Mangueira (Campo Mourão, PR) e Artur Cesar Vigilato - Fazenda Santa Teresinha (Luiziana, PR).

A análise sobre os riscos ambientais a que as áreas estão expostas demonstrou que o uso do solo para a agricultura intensiva nos arredores das RPPNs, as estradas rurais sem manejo adequado, a pesca e caça ilegais, além das espécies invasoras e exóticas, são as principais ameaças à conservação da biodiversidade. Entretanto, essas ameaças não inibem a importância das RPPNs, uma vez que são áreas de reconhecido valor conservacionista, pois, além da conservação fitogeográfica e de solo, apresentam a função de mata ciliar, protegendo os corpos hídricos.

Diante desses aspectos, considera-se que a caracterização geoecológica, compreendida como etapa inicial para o desenvolvimento de estudos ambientais, foi desenvolvida de maneira satisfatória. Os levantamentos e análises produzidas possibilitaram organizar um acervo de informações sobre as RPPNs, que poderão ser utilizadas para subsidiar outros trabalhos sobre essas áreas, bem como colaborar para a organização dos planos de manejo desses espaços.

O uso dos perfis geoecológicos permitiu, ainda, a aplicação do enfoque sistêmico neste estudo. Para tanto, é importante ressaltar que para isso é preciso que os elementos cartografados estejam em maior número possível, evitando, assim, uma visão parcial ou distorcida do que foi pesquisado. Nesse sentido, a caracterização descritiva dos elementos envolvidos é importante, já que a quantificação é algo complexo em relação à paisagem devido à dinâmica envolvida (LEVIGHIN; VIADANA, 2003).

O uso da técnica de construção de perfil geoecológico, portanto, demonstrou ser eficiente para alcançar o objetivo do estudo, bem como evidenciou que pode ser considerado instrumento para o desenvolvimento de estudos da área ambiental.

\section{REFERÊNCIAS}

ANDRADE, T. Inovação tecnológica e meio ambiente: a construção de novos enfoques. Ambiente \& Sociedade, v.7, n.1, p.89-106, 2004.

BERTRAND, G. Paisagem e Geografia física global: esboço metodológico. Cadernos de Ciência da Terra, n.13, p.1-27, 1971.

BRASIL. Lei n. 9.985, de 18 de julho de 2000. Regulamenta o art. 225, § $1^{\circ}$, incisos I, II, III e Vll da Constituição Federal. Institui o Sistema Nacional de Unidades de Conservação da Natureza. Diário Oficial da República Federativa do Brasil. Brasília: 2000.

BRASIL. Decreto ${ }^{\circ}$ 5.746, de 5 de abril de 2006. Regulamenta o art. 21 da Lei no 9.985, de 18 de julho de 2000, que dispõe sobre o Sistema Nacional de Unidades de Conservação da Natureza. Diário Oficial da República Federativa do Brasil. Brasília: 2006.

EMPRESA BRASILEIRA DE PESQUISA AGROPECUÁRIA - EMBRAPA. Mapas de solo do estado do Paraná: escala 1:250.000. Rio de Janeiro: Embrapa Solos, 2007.

FERREIRA, L. M.; CASTRO, R. G. S.; CARVALHO, S. R. C. Roteiro metodológico para elaboração de plano de manejo para reservas particulares do patrimônio natural. Brasília: IBAMA, 2004. 96p.

INSTITUTO AMBIENTAL DO PARANÁ - IAP. Diretoria de Biodiversidade e Áreas Protegidas. Plano de Manejo do Parque Estadual Lago Azul. 2005 - Curitiba: IAP/DIBAP, 2005. 270p. Disponível em: <http://www.uc.pr.gov.br/ modules/conteudo/conteudo.php?conteudo=37>. Acesso em: 26 jan. 2012.

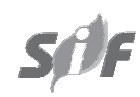

Revista Árvore, Viçosa-MG, v.38, n.5, p.907-917, 2014 
INSTITUTO AMBIENTAL DO PARANÁ - IAP. Roteiro para Planejamento de RPPNs no Estado do Paraná. Paraná: IAP/DIBAP/ DBio e DUC / Projeto Paraná Biodiversidade, 2009. 72p. Disponível em: <http:// www.uc.pr.gov.br/arquivos/File/RPPN/ Roteiro_Metodologico/ Roteiro_Metodologico_PM_RPPN_pdf.pdf $>$. Acesso em: 26 jan. 2012.

INSTITUTO AGRONÔMICO DO PARANÁ IAPAR. Cartas Climáticas do Paraná. Londrina, Paraná. Disponível em: <http:// www.iapar.br/modules/conteudo/ conteudo.php?conteudo=595>. Acesso em: 11 jan. 2012.

\section{INSTITUTO DE TERRAS, CARTOGRAFIA E GEOCIÊNCIAS - ITCG. Formações} Fitogeográficas - Estado do Paraná. Articulação: 1 folha. 2009. Escala 1:50.000. Disponível em: < http://www.itcg.pr.gov.br/ arquivos/File/Produtos_DGEO/Mapas_ITCG/PDF/ Mapa_Fitogeografico_A3.pdf $>$. Acesso em: 28 de out. 2011.

LEVIGHIN, S. C.; VIADANA, A. G. Perfis Geoecológicos como técnica para os estudos das condições ambientais. Sociedade \& Natureza, v.14/15, p.5-14, 2002/2003.

MANOSSO, F. C.; NÓBREGA, M. T. A estrutura geoecológica da paisagem como subsídio a análise geoambiental no Município de Apucarana-PR. Revista Geografar, v.3, n.2, p.86-116, 2008.

MANOSSO, F. C. Estudo integrado da paisagem nas regiões norte, oeste e centro-sul do estado do Paraná: relações entre a estrutura geoecológica e a organização do espaço.

Boletim de Geografia, v.26/27, n.1, p.81-94, 2008/2009.

MATEO RODRIGUEZ, J. M.; SILVA, E. V.; CAVALCANTI, A. P. B. Geoecologia das Paisagens: uma visão geossistêmica da análise ambiental. Fortaleza: UFC, 2004.

MEDEIROS, R.; PEREIRA, G. S. Evolução e implementação dos planos de manejo em parques nacionais no Estado do Rio de Janeiro. Revista Árvore, v.35, n.2, p.279-288, 2011.
MEZZOMO, M. D. M. Utilização de perfis geoecológicos como técnica para o estudo da paisagem. In: ENCONTRO NACIONAL DA ANPEGE, 8., 2009, Curitiba. Anais... Curitiba: UFPR, 2009. v. 1. p.1-12.

MEZZOMO, M. D. M. Considerações sobre o termo "paisagem" segundo o enfoque Geoecológico. In: NUCCI, J. C.(Org.). Planejamento da paisagem como subsídio para a participação popular no desenvolvimento urbano. Estudo aplicado ao bairro de Santa Felicidade - Curitiba/PR. Curitiba: LABS/ DGEOG/UTFPR, 2010. p.1-13.

MINEROPAR - Serviço Geológico do Paraná. Atlas Geológico do Estado do Paraná. 2001. 116p. Disponível em: <http://

www.mineropar.pr.gov.br/arquivos/File/2_Geral/ Geomorfologia/

Atlas_Geomorforlogico_Parana_2006.pdf> . Acesso em: 27 de out. 2011.

MINEROPAR - Serviço Geológico do Paraná. Atlas Geomorfológico do Estado do Paraná. Escala Base: 1:250.000 com Modelos Reduzidos de 1:500.000. 2006. 63p. Disponível em: <http://www.mineropar.pr.gov.br/arquivos/File/ 2_Geral/Geomorfologia/

Atlas_Geomorforlogico_Parana_2006.pdf > . Acesso em: 27 de out. 2011.

MINEROPAR - Serviço Geológico do Paraná. Carta Geológica de Campo Mourão. Articulação: SG.22-V-B. Paraná, 2005. 21 folhas. Escala: 1:250.000. Disponível em: <http:// www.mineropar.pr.gov.br/arquivos /File/2_Geral/ Geologia/PDF_Mapas_Geo_250000/

Campo_Mourao.PDF>. Acesso em: 25 de out. 2011.

MINEROPAR - Serviço Geológico do Paraná. Mapa de Vulnerabilidade Geoambiental do Paraná. Disponível em: <http://www.mineropar.pr.gov.br/arquivos/File/ 2_Geral/Geomorfologia/

Mapa_Vulnerabilidade_Geoambiental_PR_650000_2007.pdf>. Acesso em: 28 out. 2011.

MITTERMEIER, R. A. et al. Uma breve história da conservação da biodiversidade no Brasil.

Megadiversidade, v.1, n.1, p.14-21, 2005. 
SILVA, J. B. Levantamento florístico vascular da reserva particular do patrimônio natural (RPPN) estadual Ana Tramujas, município de Campo Mourão - PR. 2009. 33f. Trabalho de Conclusão de Curso (Graduação) - Universidade Tecnológica Federal do Paraná, Curso Superior em Tecnologia Ambiental, Campo Mourão, 2009.

SILVEIRA, C. S.; SILVA, V. V. Dinâmicas de regeneração, degeneração e desmatamento da vegetação provocadas por fatores climáticos e geomorfológicos: uma analise geoecológica através de SIG. Revista Árvore, v.34, n.6, p.1025-1034, 2010.

ZILLER, S. R. Espécies exóticas da flora invasoras em Unidades de Conservação. In: CAMPOS, J. B.; TOSSULINO, M. G. P.; MÜLLER, C. R. C.

Unidades de conservação: ações para valorização da biodiversidade. Curitiba: Instituto Ambiental do Paraná (IAP), 2006. p.34-52. 